\title{
Future Space Transportation Technology: Prospects and Priorities
}

\author{
David Harris \\ Projects Integration Manager \\ In-Space Propulsion Technology Projects Office \\ Marshall Space Flight Center \\ MSFC, AL 35812 \\ David.Harris@nasa.gov
}

\author{
Matt Bille and Lisa Reed \\ Booz Allen Hamilton \\ 121 S. Tejon, Suite 900 \\ Colorado Springs, CO 80903 \\ bille_matt@bah.com / reed_lisa@bah.com
}

\begin{abstract}
The Transportation Working Group (TWG) was chartered by the NASA Exploration Team (NEXT) to conceptualize, define, and advocate within NASA the space transportation architectures and technologies required to enable the human and robotic exploration and development of space envisioned by the NEXT. In 2002, the NEXT tasked the TWG to assess exploration space transportation requirements versus current and prospective Earth-to-Orbit (ETO) and in-space transportation systems, technologies, and research, in order to identify investment gaps and recommend priorities. The result was a study now heing incorporated into future planning by the NASA Space Architect and supporting organizations. This paper documents the process used to identify exploration space transportation investment gaps as well as the group's recommendations for closing these gaps and prioritizing areas of future investment for NASA work on advanced propulsion systems.
\end{abstract}

\section{Introduction}

Achieving robotic, and eventually, human presence beyond low Earth orbit (LEO) will require an agency-wide commitment of NASA centers working together as "one NASA." Propulsion technology advancements are vital if NASA is to extend a human presence beyond the Earth's neighborhood.

While numerous advanced propulsion lechnologies are presently being researched and developed, it is not feasible to invest in all of them. Instead, NASA must ensure that its future mission goals are clearly defined, then identify those advanced technologies which, if funded, offer the most potential for successfully meeting those requirements.

In 2002, the NASA Exploration Team (NEXT) tasked the Transportation Working Group to assess future technology investments. The resulting report is summarized in this paper.'

The major focus of the Exploration Space Transportation Gap Analysis was to analyze numerous advanced propulsion concepts, identify their technological readiness levels, compare their capabilities to future mission requirements, and recommend technology investments needed to close gaps before the point of flight demonstration or test. The NASA Exploration Team (NEXT) was chartered to:

- Create and maintain a long-term strategic vision for science-driven human/robotic exploration

- Conduct advanced concepts analyses and develop new approaches for exploration via breakthrough technology

- Generate scientific, technical and programmatic requirements to drive technology investments which will enable each new phase of human/robotic exploration.

The basis of the NASA exploration vision is sustained development of "stepping stone" capabilities that enable affordable, sate and reliable space exploration. That vision remains in place in the NASA Space Architect support activity, which subsumed the NASA Exploration Team. A stepping stone is not a set of missions, but a level of capability. The stepping stones are displayed visually in Figure 1. 
Analysis Tasks:

The primary tasks in this analysis were:

- Research performance capabilities of existing and prospective propulsion technologies.

- Research future mission requirements as defined by the NASA Exploration Team and other enterprises within NASA.

- Compare future mission requirements to prospective propulsion technologies, identilying the most suitable technolegies.

- Map transportation requirements to technologies and capabilities, identifying technology investment gaps and making recommendations for their closure.
Technology for Human/Robotic Exploration and Development of Space (THREADS) architecture into Earth to Orbit (ETO), In-Space Propulsion, and Target-Body segments. A Design Reference Mission (DRM) set of 17 missions, covering all five Stepping stones identified in the NEXT vision, was derived from NEXT and other NASA mission planning documents.

- Missions were mapped to technologies. The DRMs used ranged from support io the International Space Station all the way to Human Outer Planet Exploration and an interstellar probe. For each DRM, the prospective were identified. Then a scoring exercise was performed in which each technology was scored against 11 criteria by independent experts. The weighting of criteria was then applied to the raw scores.

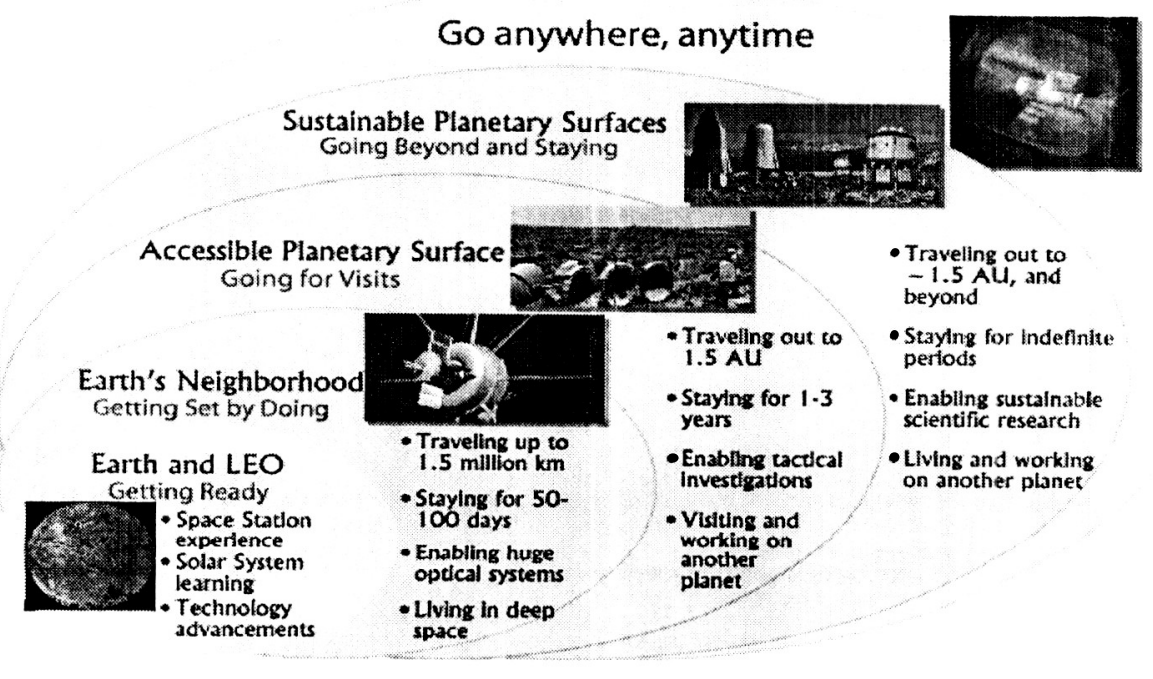

Figure 1- NEXT Stepping stones

\section{Gap Analysis Process:}

The gap analysis was accomplished in four major steps described below and shown in Figure 2.

- Data was gathered on mission requirements and technologies. A total of 22 technologies, many of which have several variants, were analyzed. These were categorized according to NASA's
- Technology gaps were identified. For each technology, publications and experts in the relevant field were surveyed to identify the gaps between the current state of the technology and Technology Readiness Level (TRL) 6 the prototype demonstration stage. (The NASA TRL scale runs from I ("basic principles observed") to 9 ("flight proven").) 
- Alternatives were recommended to close the gaps and prioritize areas of investment for future NASA projects. Finally, priorities were recommended for future investment. Recommendations for follow-on studies focusing on specific technologies needing further discrimination were also developed.

Earth-to-Orbit (ETO) transport includes those systems or technologies that enable missions from the Earth to low earth orbit (LEO). InSpace transport includes those systems or technologies that enable transport to and from various points in space. Target-Body transport lechnologies are used when arriving and departing other celestial bodies.

\section{Technologies Examined: ${ }^{3}$}

\section{State of the Art (SOA) Chemical Rockets}

Current rockets use mainly chemical propulsion, burning solid or liquid fuel with an oxidizer. Variations of this include hybrid propellant systems, in which solid fuel is burned with liquid oxygen, and a variety of exotic fuels. Theoretically, current chemical rocket technology could perform most of the DRMs examined in this analysis. Such propulsion is not, however, sustainable and affordable for long duration missions. While research in chemical propulsion promises efficiency gains, it will not enable new classes of missions.

\section{Advanced Chemical Rockets}

Some currently-researched chemical fuel improvements (which often also require changes in engine design) include advanced hydrocarbon fuels and high energy density matter (HEDM) propellant (which includes exotic propellants as well as energetic molecules added to currently-used propellants). A class of propellants called recombination energy fuels or atomic fuels might increase specific impulse $\left(\mathrm{I}_{\mathrm{sp})}\right.$ to 550 $700 \mathrm{sec}$. These improvements are currently at widely varying TRLs, from 2 to 7 .
Advanced Vehicle/Engine Designs

There are several innovative designs 10 improve the efficiency of a rocket-powered craft for the Earth-to-Orbit journey. An example is the Rocket-Based Combined Cycle (RBCC) propulsion system. By injecting fuel at various locations, the RBCC engine can operate as an air-augmented rocket, ramjet, scramjet, or pure rocket. This provides a high $\mathrm{I}_{\mathrm{s}}$, while operating in the most propellant-economical mode for any given point in the trajectory while delivering highly variable thrust levels. Other options include pulse-detonation engines, the Turbine-Based Combined Cycle (TBCC) engine, and the Air Collection and Enrichment System (ACES).

\section{Ion Propulsion (Gridded Ion thruster)}

Ion propulsion systems are in limited use for in-space applications. Producing high $I_{s p}$ but low thrust over long periods, an ion system. with xenon ions accelerated through electrostatically-charged grids, was used on NASA's 1998 - 2001 Deep Space I (DS1) mission. DSI used a system developed at NASA Glenn Research Center (GRC). This thruster, $30 \mathrm{~cm}$ in diameter, accelerated the spacecraft to a velocity of 3.5 kilometers per second $(\mathrm{km} / \mathrm{sec})$ over a 20 -month period. GRC is developing the NASA Evolutionary Xenon Thruster (NEXT) system. Such a thruster can be powered by either a solarelectric source or a nuclear-electric source.

\section{Solar Thermal Propulsion (STP)}

STP uses a concentrator cone or more parabolic mirrors, which in some designs are inflatable structures) to focus and direct solar radiation, a store of propellant (usually hydrogen), and an absorber/thruster which uses the solar energy to heat, expand, and expel the propellant to produce thrust. STP produces an $I_{s p}$ of $800-1000$ seconds. Compared to ion propulsion, STP offers a higher thrust-to-weight ratio. Raising a payload from LEO to geosynchronous orbit (GEO) using STP would take an estimated 30 days. This may nol be suitable for humans, but is attractive for cargo missions. 


\section{Ion Propulsion - Hall Effect Thruster}

The Hall Effect Ion thruster has also been used in space. A Hall Effect thruster (often abbreviated HET) uses a magnetic field to create an axial electric field, driving ions from the engine at high velocities without the use of grids. Compared to a gridded ion thruster, a Hall Effect Ion thruster works at a lower exhaust speed and thus lower $I_{s, 3}$ (for example, one type produces 30 newtons of thrust at an exhatust speed of $15 \mathrm{~km} / \mathrm{sec}$.) NASA GRC is overseeing a project to create a high-performance Hall system. Like a gridded ion system, a Hall Effect can be powered by either a solar electric source or a nuclear electric source. A two-stage barium Hall thruster, now under development at Stanford University, promises significantly increased performance.

\section{Nuclear Electric Propulsion (NEP)}

At least (wo NASA centers are actively investigating NEP technology. A program in the Advanced Propulsion Concepts (APC) office at NASA's Jet Propulsion Laboratory (JPL) is conducting NEP studies divided into three performance regimes:

- Near-term: Systems involving 0.1 1 megalwatt of electricity (MWe), requiring $18 \mathrm{~kg}$ of propulsionsystem mass per kilowatt of energy produced $(18 \mathrm{~kg} / \mathrm{kWe})$

- Mid-term systems: 1-50 mWwe, requiring $4.3-4.6 \mathrm{~kg} / \mathrm{kWe}$

- Long-term systems, operating at $100 \mathrm{MWe}$ and requiring only 0.5 $\mathrm{kg} / \mathrm{kWe}$.

NASA Marshall Space Flight Center (MSFC) is conducting the Safe Affordable Fission Engine (SAFE) test series. Its goal is the demonstration of a $300-\mathrm{kW}$ flight conliguration system using non-nuclear testing. Several fission reactor types, from the relatively mature solid-core to the unproven but promising vapor core, are being evaluated. The actual thrust on a NEP system could come from any of live types of thrusters:

- Gridded Ion Thruster

- Magnetoplasmadynamic (MPD) Thruster

- Hall Effect Thruster

- Variable Specific Impulse Magnetoplasma Rockel (VaSIMR)

- Pulsed Inductive Thruster

Nuclear Thermal Propulsion (NTP)

Nuclear thermal rockets provide thrust by expanding fuel (usually hydrogen) as it's pumped through a solid-core nuclear reactor. The United States ground-tested such systems in the NERVA program (19611971), although this technology base has deteriorated over time. One design for a nuclear thermal rocket (NTR) could produce 67,000 newtons of thrust $(6,382$ kilograms of force) with an exhaust velocity of 9 $\mathrm{km} / \mathrm{sec}$.

\section{Variable Specific Impulse Plasma Rocket (VaSIMR)}

VaSIMR attempts to circumvent the inverse relationship between $I_{s \mid}$ and thrust. In this concept, a five-step process would produce and expel a hot plasma (up to) 1 million Kelvin) contained in a "duct" created by magnetic fields and expelled via a magneticfield "nozzle." The use of the magneticfield nozzle, which can be shaped as needed. and freedom from the temperature limits imposed by material nozzles, in theory would give the VaSIMR a flexibility rockets with material nozzles of fixed dimensions cannot achieve. This, combined with the ability to change the plasma's characteristics by changing the power applied to different stages of the process, would give the VaSIMR an ability comparable to shifting gears in an automobile. However, some experts are concerned about the efficiency of such a complex system, and the concept remains unproven.

\section{NTP/NEP Bimodal or Hybrid}

A "bimodal" or "hybrid" design would use a single reactor to power a nuclear thermal 
rocket or a nuclear-electric thruster. It would use NTP to provide the high T/W ratio to climb out of a planet's gravity well, and thereafter use NEP 10 travel the Interplanetary leg of a mission with a high $I_{s p}$ at a lower thrust. The NTP reactor would be operated at low power to heat a working fluid in a closed-loop system to produce electricity in NEP mode. A variation of this system would involve two reactors, each optimized for its propulsion mode.

\section{Pulsed Inductive Thruster (PIT)}

A Pulsed Inductive thruster is a form of plasma propulsion using perpendicular electric and magnetic fields to accelerate a gaseous propellant, such as argon. The propellant interacts with a flat coil of wire energized by a brief pulse from a power source, such as a bank of capacitors. The circular electrical field induced in the gas ionizes the gals and makes the ions move in a direction opposite to the original pulse of current. This motion is perpendicular to the magnetic field, so the ions are driven out the spacecraft's nozzle at high speed. One of the attractions of PIT is scalability. The thrust and specific impulse can be adjusted by changing the discharge power, pulse repetition rate, and propellant mass flow. the power can be increased by sending pulses more frequently. For example, a $1 \mathrm{~mW}$ PIT would use about 200 pulses per second.

\section{Magnetoplasmadynamic Thruster (MPD)}

The MPD thruster uses a central cathode, which is surrounded by a concentric anode. An electrical arc between the anode and cathode ionizes gas into a plasma which is accelerated and used as propellant. Variations include the self-field MPD thruster. in which an azimuthal magnetic field generated by the current returning through the cathode interacts with the radial discharge current flowing through the plasma to produce an axial electromagnetic body force, providing thrust. In the applied field MPD thruster, a magnetic field coil surrounding the anode provides additional radial and axial magnetic fields that can help stabilize and accelerate the plasma propellant. In tests at NASA Glenn Research Center (GRC), current comes from a capacitor bank that can provide up 1030 MW to the thruster for 2 msec.

\section{$\underline{\text { Fusion }}$}

Fusion is the combining of atoms, as opposed to the "atom splitting" of fission. Efforts to produce controlled fusion reactions with net positive energy output for the production of electric power on Earth have so far been unsuccessful, although the designs used in this process are not the same as those proposed for space transportation. While several approaches to fusion reactors for space propulsion have been examined, MSFC research is presently focusing on a technique called magnctized target fusion (MTF). In this approach, a circle of plasma "guns" is fired at a toroid of magnetized plasma, compressing the target plasma enough to create fusion conditions. Fusion reactions produce plasma that is electrically conductive and exists at extremely high temperatures. The plasma can be controlled by magnetic fields to produce thrust.

\section{Solar Sail}

While a solar sail has yet to be demonstrated in spaceflight, the principles are well established. The solar sail uses a large expanse of highly rellective material so light that the pressure of sunlight (photons) alone will propel it. The thrust is very low. but continuous, and there is no propellant cost. A solar sail craft can "tack" the way a sailboat does to change direction. A perfectly reflective surface could produce 9 newtons of thrust per square kilometer of sail at a distance of 1 astronomical unit (AU) from the sun. As the spacecraft moves outward from Earth, the energy drops off by the square of the distance to the sun. The two key design drivers of solar sail are the areal density (mass per unit area) of the sail and the sail's area. Several variations on the solar sail concept were too immature for a thorough evaluation. These include the electrostatic dust sail (an ultra-lightweight sail of particles coupled clectrostatically. 
rather than physically, to the payload), and sails powered by concentrators producing beams of sunlight.

\section{Magnetic Sail or Plasma Sail (M2P2)}

A magnelic sail (or mini-magnetosphere propulsion system (M2P2)) would use a magnetic field around the spacecraft for either primary or supplementary propulsion. A plasma would be created within the magnetic lield, increasing the interaction with the charged particles of the solar wind and providing more thrust. A source of hydrogen or other propellant would need to be included, and the magnetic confinement outside the spacecraft is of uncertain integrity - the propellant will "leak" and need replacement.

\section{MXER (Momentum Exchange/Electrodynamic Reboost) Tether}

A momentum exchange (MX) tether in LEO can "swing" payloads into higher orbits or hyperbolic escape trajectories. There are several ways (o) apply this idea, but all are based on the same principle: by linking a smaller object (the payload) with a fastmoving tether tip, the payloads' speed may be dramatically increased by the transfer of momentum. In the MX concept a spinning, tether-based satellite in LEO would "dock" its tip with slower-moving objects from the surface and hurl them into higher orbits or toward destinations at or beyond Mars.

Another version of this idea is the electrodynamic (ED) tether, which uses a wire deployed from a spacecraft to generate current by moving through a planet's magnetic field. The electricity generated can be used to power thrusters for orbit raising and lowering. A flight test (the ProSEDS flight) is scheduled for 2003. This system will work on any planet with a substantial magnetosphere. A combination of the two ideas is called the MXER tether.

\section{Beamed Encrgy (laser or microwave)}

In this concept. lasers or microwaves from the ground power craft from Earth to LEO.
In October 2000, a laser-boosted model weighing 51 grams ( $g$ ) was propelled in free flight to an altitude of $71 \mathrm{~m}$ in al 13-second flight. NASA MSFC has funded continued work led by Rensselaer Polytechnic Institute to develop experimental laser "lightcraft." The attraction is the prospect of putting payloads in LEO for only the cost of the energy used (once investment costs are recouped). While the principle has been validated, lasers or microwave emitters orders of magnitude larger than those available today would be required to propel multi-ton craft into LEO.

\section{In-Space Beamed Energy}

There are several concepts to use beamed energy in space. In the pellet-pushed idca, small pellets are accelerated from a source (for example, in GEO around Easth) and guided to a spacecraft, where they are intercepted so their momentum is transferred to the spacecraft. Another version uses a microwave beam. In theory, a highly efficient design could be accelerated to a high fraction of the speed of light. A variation is the laser-propelled sail, which is driven by photons beamed from a laser station in solar orbit.

\section{Antimalter}

The annihilation of matter and antimatter is the most powerful energy- liberating reaction known to physics. The reaction considered for space transportation involves the mixing of protons and anti-protons. This reaction produces charged particles that might be directed via magnetic fields to provide thrust. The challenges involved in antimatter propulsion are immense. Controlling and directing the energy of antimatter collisions will require major technological breakthroughs.

\section{Launch Assist}

Launch assist involves using a magnetic levitation track or rockel-powered sled to provide a launch vehicle with a dela-V boost, to subsonic or supersonic speeds. to reduce the onboard propellant requirements. 
The vehicle can be launched horizontally (which has operability advantages), after which air-breathing engines and/or rockets take over for the remainder of the ascent. Magnetic levitation systems or rocketpowered launch sleds are the most commonly proposed approaches. There are also proposals for accelerating payloads to orbital speeds from a magnetic levitation track or a light gas gun. Assuming such schemes are feasible, the high acceleration and limited payload per shot involved restricts them to launching inert matter (such as fuel) into LEO.

\section{Aerocapture}

Aerocapture - the use of a planet's atmosphere to slow an arriving spacecraft is a proven approach to saving fuel. It has been used on Mars probes. In those instances, the spacecraft itself, or its solar panels, were structures affected by the atmosphere. More sophisticated concepts envision a specialized structure attached to the spacecraft. A broad, convex disk that serves both as an aerocapture device and a heat shield is one approach. Another idea is (1) trail a parachute or similar device behind the spacecraft. In the ballute approach, a torus-shaped balloon (hence the name - balloon + parachute) is used.

\section{Gravity Assist}

Gravity assist by means of the "slingshot" effect obtained via close planetary flybys has become an integral part of the conventional approach to deep-space missions, enabling visits to the edge of the solar system. Gravity assist can accelerate spacecraft to higher velocities than chemical rockets. Refinement of gravity models and trajectory programs continues.

\section{Aerogravity Assist}

The gravity assist effect might be increased by the use of aerogravity assists - missions in which a spacecraft designed as (or contained inside) a lifting body would actually descend into the upper atmosphere of a flyby body. Designing the system to cope with the extreme heating induced by atmospheric transit at high speed - without adding too much weight - is a major challenge facing aerogravity assist technology.

Technology Development: A wide range of contributing technology programs provide critical inputs to the broad area of future propulsion. Microelectronics and materials

Very Far Term (Post 2020)

\begin{tabular}{|c|c|c|c|}
\hline \multicolumn{2}{|c|}{$\longrightarrow$} & \multicolumn{2}{|l|}{ ETO } \\
\hline $\begin{array}{l}\text { - Pursue OSP } \\
\text { - Develop Next-Gen } \\
\text { Requirements } \\
\text {-Downselect \& } \\
\text { develop AVE, } \\
\text { hypersonic }\end{array}$ & $\begin{array}{l}\text { - Field OSP } \\
\text { - Develop Next-Gen } \\
\text { Technology } \\
\text { - Research alt ETO } \\
\text { technology }\end{array}$ & $\begin{array}{l}\text { - Field Next-Gen RLV } \\
\text { - Field alt ETO technology } \\
\text { (if cost-effective) }\end{array}$ & $\begin{array}{l}\text { - Full Migration to Next- } \\
\text { Gen Architecture }\end{array}$ \\
\hline & $\longrightarrow$ & In Space & $\longrightarrow$ \\
\hline $\begin{array}{l}\text { - Continue ion thruster } \\
\text { development } \\
\text { - Test \& field } \\
\text { Solar Sail } \\
\text { - Further test STP, } \\
\text { Plasma technologies } \\
\text { - Research Nuclear } \\
\text { Fission \& Fusio }\end{array}$ & $\begin{array}{l}\text { - Field advanced solar } \\
\text { thrusters (downselect to } \\
\text { HET or Gridded lon) } \\
\text { - Downselect to } 2 \text { plasma } \\
\text { options, develop \& test } \\
\text { - Space-test fission } \\
\text { reactor }\end{array}$ & $\begin{array}{l}\text { - Select and deploy } \\
\text { nuclear-powered thrusters } \\
\text { (Ion, plasma) } \\
\text { - Research in-space } \\
\text { beamed energy, antimatter }\end{array}$ & $\begin{array}{l}\text { - Field highly advanced } \\
\text { propulsion (likely } \\
\text { fusion) } \\
\text { - If antimatter or } \\
\text { beamed energy appears } \\
\text { feasible, continue R\&D }\end{array}$ \\
\hline- & $\longrightarrow$ & Target-Body & $\longrightarrow$ \\
\hline $\begin{array}{l}\text { - Continue aero- } \\
\text { capture research } \\
\text { - Improve chemical } \\
\text { thrusters }\end{array}$ & $\begin{array}{l}\text { - Continue aerocapture \& } \\
\text { chemical research, testing }\end{array}$ & $\begin{array}{l}\text { - Field advanced } \\
\text { aerocapture, } \\
\text { chemical } \\
\text { technologies }\end{array}$ & $\begin{array}{l}\text { - Continue fielding } \\
\text { advancements }\end{array}$ \\
\hline
\end{tabular}

Figure 2 - Technology Roadmap

American Institute of Aeronautics and Astronautics 
development are examples. Three areas of "cross cutting" technology applicable to multiple propulsion options stood out as deserving of a high level of effort and funding. These were 1) compact spacequalified nuclear fission reactors; 2) lightweight superconducting magnets requiring less power and operating over a wider range of temperatures then those available today; and 3) technology for the electromagnetic containment and direction of plasmas.

\section{Key Recommendations:}

\section{Propulsion Technology Recommendations by NASA Program or Enterprise:}

\section{In-Space Propulsion}

The In-Space technologies that require investment can be categorized by time phase. In the near term, solar sails offer several advantages, including lowering the requirement for initial mass to LEO (IMLEO). For the midterm, nuclear-powered options are generally superior in flexibility and capability to solar ones. Ion thrusters (both Hall Effect and gridded types) will likely progress through an advanced solar-powered phase until nuclear power is available. It is logical to continue funding while investigating the technology required to scale up these thrusters, with a downselect in a few years hased on the results. One or more options ollering higher thrust should be added to whichever of these systems is pursued further. Two plasma-based technologies, the PIT and MPD thrusters, appear feasible at this point. If further review deems it feasible, VASIMR could be an intriguing option, offering as it does a single unit providing a highly flexible performance range. If VASIMR is not pursued, an architecture involving development and of a high- and low-thrust system, such as MPD and one of the ion types, should be funded.

Challenges facing in-space beamed energy technology and M2P2 are, at this point, highly complex, and increased funding for these is not recommended in the near term.

While budgets often drive downselect decisions to a point in lime, it is crucial to avoid such a situation, and not downselect prematurely. The decision time should be based on the achievement of a suitable level of maturity.

MX tethers are a special case. The physics are straightforward, but the engineering problems of orbiting a sufficient mass and operating it as envisioned by tether proponents are formidable. ED tethers, although their use is limited (primarily to lowering and raising of orbits in planetary atmospheres) appear to be a promising and affordable investment.

Gravity assist is a proven approach for planetary missions, and efforts to refine the trajectory design and gravity models are inexpensive and well worth supporting. Acrogravily assist is a longer-term prospect with limited (albeit intriguing) applications. Since the Department of Defense is investigating "waverider" hypersonic craft using designs applicable 10 aerogravity assist, near-term experimentation with this concept is likely to be funded by others, with NASA support required only in a coordinating role. Continued development of aerocapture technology for orbiting or entering planetary atmospheres is highly recommended, given its ability to reduce mission mass.

\section{Orbital Space Plane (OSP)}

The OSP, the first human-carrying segment of the ISTP (as revised in late 2002), is based on SOA Chemical propulsion with incremental improvements. Since the OSP vehicles will likely be in service for two decades or more, their designs should be capable of accepting upgraded SOA Chemical technologics throughout that lifetime. Over the same lime period, In-Space propulsion technologies will be pursued for upper stages, orbit transfer, and interplanetary missions. The nuclear-powered options add safety concerns and will result in relatively dense payloads, while systems powered by solar panels will require larger volumes. Solar Thermal propulsion, if pursued, adds the requirement for large quantities of hydrogen propellant to be lifted into LEO. While the OSP is focused on the transfer of astronauts as its primary mission, the flexibility to adapt the vehicle to other uses (crewed or robotic) and other propulsion systems should be carefully examined 


\section{Next Generation Hypersonics}

NASA's Space Transfer and Launch Technology (STLT) under the Office of Aerospace Technology (Code $R$ ) is charged with the hypersonic technology elements of the Next Generation RLV plan. This includes rocketbased combined-cycle and turbine-based combined-cycle engines, high-speed scramjets, and related technology. The planned review of these three major night propulsion approaches in 2003 should progress, with further downselects based on the progress of the technology and the applicability to partners like USAF and DARPA, which are also funding hypersonic technology. The two most promising approaches should be funded through flight demonstrators (already planned for scramjets and potentially a RBCC or TBCC prototype under the Hyper-X program).

\section{Next Generation RLV}

The Next Gen system can be expected to rely on Advanced Chemical fuels (if these are found suitable for man-rated vehicles) and Advanced Vehicle/Engine (AVE) designs. Since the RLV will remain fundamentally rocket-based, efforts should go forward to refine the Next Gen requirements, with attention to the mass, velocity, and other requirements which are mandated by NASA's Orbital Aggregation and Space Infrastructure (OASIS) goals. These requirements will drive the prioritization of the Advanced Vehicle/Engine (AVE) development efforts. Given that there are many variations on the AVE concepts, technology development efforts should, in the short term, be made on a broad front, with a downselect around TRL 4-5 to two systems which 1) show the most technological promise and 2) are most suited to the NextGen requirements. It should be kept in mind that, as with the $2^{\text {nd }}$ Gen selection, the InSpace propulsion technologies pursued will affect the choice of suitable ETO technologies.

\section{Nuclear Systems Initiative (NSI)}

NSI (and its current Project Prometheus) is a critical program for the future of NASA. Given the power and range limitations of solar-powered technologies, advanced-design, compact, safe nuclear fission rcactors suitable for space use are the "long pole" in the satisfaction of In-Space
Propulsion requirements for future Stepping stone architectures. At this point, Nuclearpowered Hall or Gridded Ion thrusters appear to be the most promising areas of near-term development. If the combination of Nuclear Thermal Propulsion and Nuclear Electric Propulsion (NTP/NEP Bimodal/Hybrid technology) proves cost-effective, it can be pursued in the mid-term to offer a capable foundation for the Stepping Stone 4 (Sustainable Planetary Surface missions) architecture. In any event, high priority is deserved for development under the NSI of a suitable reactor for the energy supply to a propulsion system, with the same technology applicable to powering outposts on Mars and the outer planets. The Jupiter Icy Moons Orbiter (JIMO) test mission now under development should be a NASA and national priority. The political difficulties with nuclear reactors must be addressed directly, and the program continued under the strictest of safety and security protocols in spite of opposition.

\section{Revolutionary Propulsion Research}

For missions directed at sending probes to other star systems, and perhaps to the Human Outer Planet Exploration mission, Fusion or Antimatter systems will be required. At this point. Fusion appears the more feasible of the iwo, while Antimatter could, in theory. provide the highest power and greatest velocity of any prospective system. A large near-term investment in a system that may be impractical (Antimatter) seems unwarranted. The Fusion approach is not only more promising, but offers considerable synergy with Fusion power development on Earth. Accordingly, Fusion is recommended for continued or increased funding commensurate with its technology readiness level, with lowerlevel theoretical and component work on Antimatter continuing.

\section{Additional Studies}

Additional studies are warranted concerning:

- Next Gen RLV propulsion. The ETO propulsion options need to be examined in more detail, compared to developing requirements, and narrowed down (1) prioritize investment. 
- In-Space Propulsion. There are several competing technologies that are not ready for infusion into flight missions at the current level of maturity. An ongoing effort, perhaps with an annual review for the next lew years, seems appropriate, with a downselect for flight demonstration(s) as the ultimate goal.

- Requirements to LEO. Taken together, the DRMs create a broad range of requirements for lifting masses to $\mathrm{LEO}$. Within these missions are many variables, including the size of payloads, the urgency and responsiveness of launch, and the type of materials to be launched. Development of a more specific mission model - tentative though it must be - is important to permit prioritization of the related ETO technologies.

- Optimal Technologies for Distant Crewed Missions. The nuclearpowered electromagnetic technologies are the most promising nearer-term options, followed (in probable development time) by NTP or perhaps NTP/NEP Hybrid/Bimodal. The study needed to characterize the merits of the conceptual designs for human missions, while a follow-up study examining the Hybrid/Bimodal designs and architectures (reactor type, single vs. dual reactor, etc.) for humans need not be performed immediately. The relative merits of these options may not be characterized until TRL 6 is reached (assuming all are developed that far).

\section{Looking at Trade-Offs}

In a zero-sum budget world, it is important to identify technologies that can be de-emphasized in short-term funding without harming the overall progress through the NEXT Stepping stones. Decision-makers in the structure which has replaced NEXT, including the cross-agency Space Transportation Team and NASA Space Architect, inevitably will have to make the decision not to fund, or to fund only at low levels, some of the technologies in this report.
The items likely to be low priorities are those applying to few missions or those too far out in time to merit a near-term boost. Antimatter and In-Space Beamed Energy are too immature 10 evaluate. The same might be said of Fusion. but basic research on one longer-term solution should be funded now. and Fusion is the most attractive. NTP and NTP/NEP Hybrid or Bimodal, likewise, need not be heavily funded in the short term. Work on NEP, which appears a more promising candidate to make practical contributions sooner (and is baselined for the JIMO mission), will provide technology to these efforts when and if they are required.

\section{Technologies for Crewed vs. Robotic Missions}

All the technologies examined are suitable for robotic missions, and most, if not all, new technologies will he tested on such technologies before being considered for crewed missions. Identifying technologies for human missions is mainly a process of exclusion which lakes into account the particular missions.

All ETO technologies examined are potentially suitable for humans. The Beamed Energy ETO is probably the most problematic of these, given that humans can ride only in relatively large space vehicles, and humans will not be placed in a vehicle without a backup propulsion system in the event of failure of the laser or maser.

Of the In-Space technologies, a few stand out as unlikely to be used for humans. MX Tethers are an example. The stresses placed on the payload vehicle would have (1) be thoroughly characterized before human Iransport was considered. Aerogravity assist (AGA) is likewise problematic. The stresses likely to be placed on a vehicle using this technology are very high, and the problems of designing a craft for AGA with space for a human crew (given the high $\mathrm{L} / \mathrm{D}$ needed for vehicles using AGA) will keep AGA "out of the tradespace" for human missions for at least the near-10 mid-term, if not permanently. By that point, a technology like fusion may be developed that eliminates or reduces the utility of $A G A$ for such missions.

Placing humans on nuclear-powered (fission or fusion) missions requires additional consideration (and probably mass) be given to 
shielding. Keeping in mind that humans also need shielding from In-Space radiation, a crewed vehicle for long-distance space flight is likely to be a very large and heavy structure. It seems unlikely that solar sails will have the capacity for such missions. Crewed missions require powered abort capabilities. Reduced travel time is more of a factor in human missions. These additional factors also rule out solar sails.

At this point, it is unclear whether the ion technologies will he scalable to the point of providing the high thrust preferred for crewed missions needing rapid transport and abort capabilities. Beyond the Earth-moon neighborhood, where chemical propulsion and solar-powered systems can be used (given the relatively short distances and trip times), the options for DRMs like Mars Exploration and Human Outer Planet Exploration are narrow. If we assume antimatter and In-Space beamed energy are too far off to be involved in current planning, that leaves nuclear-powered highthrust electromagnetic thrusters (PIT, MPD, and VASIMR), NTP, NEP/NTP Hybrid/Bimodal, and Fusion. NTP was developed under the NERVA program to be used for human ransportation.
Fusion is more powerful and versatile than the fission options, but is also further in the future. It is important to narrow the choices down to the most realistic options for human solar system exploration.

The architecture which emerged from analysis of the technologies posited from three to four generations of technology for human missions. The variation in this architecture exists because of technological and financial uncertainties.

\section{Conclusion:}

As NASA presses on into the challenging future of extended robotic and human presence outside the Earth-Moon neighborhood, it is imperative that new propulsion technologies be fully developed regardless of technical and political obstacles. Charting the most prudent course for this journey requires difficult judgments that may not always prove correct. The analysis in this paper is a first step in highlighting promising propulsion technologies, analyzing their capabilities, the technology gaps, and providing recommendations to aid NASA in determining where it should place its luture investments.

\begin{tabular}{|l|c|l|l|}
\hline $\begin{array}{c}\text { Generation of Human } \\
\text { Missions }\end{array}$ & $\begin{array}{c}\text { Stepping } \\
\text { Stone }\end{array}$ & Technology Candidates & Notes \\
\hline First (Mid Term) & 3 & $\begin{array}{l}\text { Nuclear-powered } \\
\text { PIT } \\
\text { MPD } \\
\text { VASIMR }\end{array}$ & $\begin{array}{l}\text { May skip to Second Gencration } \\
\text { options if these technologies } \\
\text { prove to take longer to develop } \\
\text { than expected, or to be } \\
\text { unsuitable }\end{array}$ \\
\hline $\begin{array}{l}\text { Second (Mid to Long } \\
\text { Term) }\end{array}$ & $3-4$ & $\begin{array}{l}\text { NTP or NTP/NEP } \\
\text { Hybrid/Bimodal }\end{array}$ & $\begin{array}{l}\text { If promising, could be "moved } \\
\text { up" to be the first generation }\end{array}$ \\
\hline Third (Long Term) & $4-5$ & Fusion & $\begin{array}{l}\text { If development proceeds } \\
\text { quickly, could make second- } \\
\text { generation nuclear unnecessary }\end{array}$ \\
\hline Fourth (Very Long Term) & 5 & Antimatter & $\begin{array}{l}\text { Advanced fusion or hybrid } \\
\text { (antimatter-initiated fusion) may } \\
\text { make antimatter drive } \\
\text { unnecessary, at least until human } \\
\text { interstellar missions are planned. }\end{array}$ \\
\hline
\end{tabular}

Table 1- Candidate Technologies for Human Exploration

DISCLAIMER: Opinions expressed in this paper are solely those of the authors. This paper does not represent the official views or policies of $\mathrm{Boo} / \mathrm{d}$ Allen Hamilton, NASA, or the U.S. Government. 


\section{Author Biographies}

David Harris is Projects Integration Manager for the In-Space Propulsion Technology Projects Office at Marshall Space Flight Center. He was a member of the NASA Exploration Team (NexT), and continues to participate in the Transportation Studies Team. Matt Bille is an Associate with Booz Allen Hamilton in Colorado Springs. Matt has published over 20 articles and papers on space technology and is co- authoring a book on the first small satellites of the 1950s. He is a Senior Member of the AIAA and a member of the History Committee of the American Astronautical Society. Lisa Reed is an Associate with Booz Allen Hamilton. She is a veteran of 15 years' Space Shuttle operations experience with NASA and the United Space Alliance, including serving as an astronaut training team leader. She is a member of the History Committee of the AAS and holds a Master's degree in Instructional Technology.

\section{ENDNOTES}

1 TWG, NEXT Space Transportation Gap Analysis. September 27, 2002.

2 Sources include: NEXT, NEXT Design

Reference Mission Summary, July 11, 2002:

MSFC, "2nd Generation Reusable Launch Vehicle Program Design Reference Missions," Rev. B, May 1, 2002: NEXT, "NEXT Inputs to the 2nd Generation Reusable Launch Vehicle Program." June 17, 2002: "Results of Next Generation In-Space Transportation Technologics: Technology Prioritization Workshop," May 14-15, 2002: Integrated InSpace Transportation Plan (ISTP) Phase I Final Report, September 14, 2001.

"Sources include: Robert L. Frisbee, JPL, "Advanced Propulsion Concepts," October 2001: Franklin R. Chang-Diaz, "The VaSIMR Rocket," Scientific American, November 2000, p.92: NASA, "An Overview of the Advanced Propulsion Research Project Office," April 2001: "Propulsion Systems," Scientific American, March 2000, p.46: John Cole, Revolutionary Propulsion Research office, MSFC, August 26, 2002: Jay Polk, "An Overview of JPL's Advanced Propulsion Concepts Research Program." April 3, 2001; NEXT, "NEXT Human Exploration Requirements for Future Nuclear Systems," Draft 4, August 26, 2002: IISTP Phase I report, p.50: Stanley K. Borowski and Robert L. Cataldo, NASA GRC, "Nuclear Thermal Rocket (NTR) Propulsion and Power Systems for Outer Planetary Exploration Missions," 2001. 